University of Nebraska - Lincoln

DigitalCommons@University of Nebraska - Lincoln

April 2000

\title{
Choosing a doctor: an exploratory study of factors influencing patients' choice of a primary care doctor
}

\author{
Brian H. Bornstein \\ University of Nebraska-Lincoln, bbornstein2@unl.edu \\ David Marcus \\ New Mexico State University \\ William Cassidy \\ Louisiana State University Medical Center
}

Follow this and additional works at: https://digitalcommons.unl.edu/psychfacpub

Part of the Psychiatry and Psychology Commons

\begin{abstract}
Bornstein, Brian H.; Marcus, David; and Cassidy, William, "Choosing a doctor: an exploratory study of factors influencing patients' choice of a primary care doctor" (2000). Faculty Publications, Department of Psychology. 178.

https://digitalcommons.unl.edu/psychfacpub/178
\end{abstract}

This Article is brought to you for free and open access by the Psychology, Department of at DigitalCommons@University of Nebraska - Lincoln. It has been accepted for inclusion in Faculty Publications, Department of Psychology by an authorized administrator of DigitalCommons@University of Nebraska - Lincoln. 


\title{
Choosing a doctor: an exploratory study of factors influencing patients' choice of a primary care doctor
}

\author{
Brian H. Bornstein, Department of Psychology, Louisiana State University \\ David Marcus, Department of Psychology, New Mexico State University \\ William Cassidy, Louisiana State University Medical Center
}

\section{Correspondence:}

Brian H. Bornstein, 238 Burnett Hall, University of Nebraska-Lincoln, Lincoln NE 68588-0308 USA

Accepted for publication May 16, 2000

\begin{abstract}
We assessed the relative importance healthcare consumers attach to various factors in choosing a primary care doctor (PCD) in a cross-sectional, in-person survey. Three survey locations were used: doctors' offices, a public shopping area, and meetings of a women's organization. A total of 636 community residents, varying across major demographic categories, participated. Participants completed a 23-item survey, designed to assess which factors consumers perceive as most relevant in choosing a PCD. Participants perceived professionally relevant factors (e.g. whether the doctor is board certified, office appearance) and management practices (e.g. time to get an appointment, evening and weekend hours) as more important than the doctor's personal characteristics (race, age, gender, etc.). Participants' own characteristics bore little relationship to the perceived importance of doctor characteristics. Factors patients perceive as most important to their choice of a PCD are also those that have the greatest effect on the quality of healthcare they will receive. However, they do not always have access to this information. A better understanding of the factors that influence people's choice of a PCD can contribute to efforts to provide them with the resources to make well-informed decisions in selecting among healthcare options.
\end{abstract}

Keywords: consumer behavior; decision making, primary care

\section{Choice of a primary care doctor}

Research on medical decision making has concentrated more on the decision-making abilities of medical practitioners (e.g. Dawson \& Arkes 1987; Detmer, Fryback, \& Gassner 1978; Elstein, Shulman, \& Sprafka 1978) than those of patients. For example, research has addressed the extent to which diagnosticians' judgments are influenced by knowledge of the correct diagnosis (i.e. the "hindsight" bias; see Arkes, Wortmann, Saville, \& Harkness 1981; Dawson, Arkes, Siciliano, Blinkhorn, Lakshmanan, \& Petrelli 1988) or the manner in which diagnostic al- ternatives are presented (i.e. "framing" effects; see Christensen, Heckerling, Mackesy-Amiti, Bernstein, \& Elstein 1995; McNeil, Pauker, \& Tversky 1984).

Some attention has been paid as well to patients' decision making. For example, research has addressed patients' ability to give informed consent (Fitten, Lusky, \& Hamann 1990; Ubel \& Loewenstein 1997) and the process by which they choose among therapeutic options (e.g. Pauker \& McNeil 1981) or make end-of-life decisions (Hofmann et al. 1997). Much of this research has shown that, as with decision making in general, patients are susceptible to cognitive biases (e.g. Asch, Baron, Her- 
shey, Kunreuther, Meszaros, Ritov, \& Spranca 1994). For example, patients, like doctors, are influenced by the manner in which treatment outcome data are presented (Mazur \& Hickam 1990).

Relatively little research has addressed one of the first decisions that patients must make; that is, the choice of a primary care doctor (PCD). Often, consumers make this decision in conjunction with choosing a particular health plan (Gibbs, Sangl, \& Burrus 1996; Lubalin \& Harris-Kojetin 1999). Thus, under managed care, an increasing number of people are required to choose a PCD even before having a need for one. What factors influence this decision? A pair of British studies (Billinghurst \& Whitfield 1993; Salisbury 1989) found that the most commonly cited factor in choosing a new doctor was convenience; and indeed, a recent large-scale survey of American patients' satisfaction with healthcare found that their most frequent complaints dealt with long waiting times (Medical Economics 1997). Recommendations from others were also influential (see also Hoerger \& Howard 1995; Lupton, Donaldson, \& Lloyd 1991). However, the conclusions that can be drawn from the British studies are somewhat limited in that they were based on samples of patients who had left their previous PCD precisely because it was inconvenient to continue (e.g. because one party had moved). Thus, it is unclear whether the importance of convenience would generalize to a population of patients not in the process of switching doctors. Billinghurst and Whitfield also used an openended response format, so patients might have failed to report relevant factors either by oversight or embarrassment. Salisbury did ask patients to rate the importance of a relatively small number of factors in choosing a doctor, but most of them concerned office organization and omitted indicators of doctors' expertise. Hoerger \& Howard (1995) found that expertise was overwhelmingly the most important determinant of women's choice of a prenatal care doctor. Finally, although these studies provide much useful data, the many differences between the British and American healthcare systems might lead patients in the two countries to emphasize very different factors in choosing a doctor.

Fischhoff \& Downs (1997) point out that behavioral decision-making research is especially help- ful in that it is capable of making people aware of what information and goals are important to them, thereby enabling them to make effective decisions and competently manage their affairs. Although research on fundamental decision processes is important, the potential contributions of such research are greatest when the research addresses highly consequential decisions that people make in the real world (Ebbesen \& Konecni 1980). A better understanding of the factors that influence people's choice of healthcare providers would potentially provide them with the resources to make better choices in this arena and consequently attain greater satisfaction with their healthcare status (Hibbard et al. 1997; Lubalin \& Harris-Kojetin 1999).

\section{Method}

\section{Participants}

Sampling was done at three sites: the waiting room of a large neurological group practice, a large general-purpose store catering to a diverse clientele, and meetings of a local women's organization. These sites were chosen to make the total sample as representative of the community as possible. We wanted to include some participants for whom healthcare was a salient issue at the time of completing the survey (i.e. patients) but who would not be influenced by the nearby presence of the target of the survey (i.e. their PCD, hence the selection of a medical specialty practice). Surveys were restricted to persons appearing to be over 20 years of age. The total sample consisted of 636 participants.

Patients $(n=206)$ were surveyed while waiting for their appointments. These participants were not paid for their participation in the survey. Over $95 \%$ of the patients approached in the doctors' waiting room agreed to participate in the survey.

Store participants $(n=201)$ were approached at the main entrance to the store and asked to participate in the survey. Approximately $85 \%$ of the store patrons who were approached in this manner agreed to participate in the survey; they were paid $\$ 2$ for their participation (piloting indicated that the response rate was unacceptably low at this site otherwise).

Women's organization participants $(n=229)$ were tested during their regular group meetings. A large 
majority of those present agreed to participate; they were not paid.

\section{Materials and design}

Survey questions were drawn from previous studies (Hoerger \& Howard 1995; Lupton et al. 1991; Wolinsky \& Streiber 1982) as well as several pilot studies in which members of diverse groups (psychology professors, graduate social work students, newspaper readers responding to a brief questionnaire included as part of a health article) were asked open-ended questions about the factors they considered important in choosing their doctor. Based on the pilot research, a final list of 23 items was developed (Table 1).

\section{Procedure}

Participants were approached and asked to participate in a survey. Preliminary instructions were read aloud to the participants, informing them that: "The purpose of this survey is to find out what types of information people would like to know in choosing a doctor. We are more interested in what you would most like to know - if you had to choose a doctor today - than in what you actually did consider in choosing your current doctor. If you could know the following when choosing a primary care doctor, how would you rate the following factors for their importance to your decision? Please use a scale of 1-10 (with 1 being of least importance, 5 of moderate importance, and 10 being of greatest importance)."

Participants then rated the importance of the 23 items. After completing the survey at their own pace, participants completed a brief demographic questionnaire. They were then thanked for their participation and debriefed.

\section{Results}

Four subjects (three patients and one store participant) were deleted due to a low response rate (de-

Table 1 Importance of factors in choosing a primary care physician

\begin{tabular}{|c|c|c|}
\hline Item & Mean & $S D$ \\
\hline Whether the doctor is board certified & 9.31 & 1.67 \\
\hline Physical appearance of the doctor's office (i.e. neatness) & 8.15 & 2.13 \\
\hline Physical appearance of the doctor (i.e. neatness) & 8.00 & 2.25 \\
\hline Recommendations from friends/family & 7.92 & 2.23 \\
\hline Specialization in a particular illness & 7.88 & 2.68 \\
\hline Which hospital(s) the doctor uses & 7.88 & 2.27 \\
\hline Waiting time for an appointment & 7.73 & 2.25 \\
\hline Whether malpractice cases filed against the doctor & 7.62 & 2.66 \\
\hline Waiting time at office visit & 7.39 & 2.37 \\
\hline Which HMO's (or insurance plans) the doctor is in & 6.93 & 3.19 \\
\hline Where the doctor attended medical school/residency & 6.79 & 2.94 \\
\hline Cost of the care (that patient must pay) & 6.46 & 3.09 \\
\hline How long the doctor has been practising & 6.33 & 2.68 \\
\hline Proximity of the doctor's office & 5.94 & 2.76 \\
\hline Whether the doctor has weekend office hours & 5.65 & 2.83 \\
\hline Whether the doctor has evening office hours & 4.98 & 2.81 \\
\hline Number of doctors in the office & 3.95 & 2.75 \\
\hline The doctor's age & 3.85 & 2.57 \\
\hline The doctor's gender & 3.29 & 3.01 \\
\hline The doctor's native country (assuming doctor's English is good) & 2.75 & 2.61 \\
\hline The doctor's ethnicity or race & 2.46 & 2.47 \\
\hline The doctor's religion & 2.06 & 2.26 \\
\hline The doctor's marital status & 1.68 & 1.92 \\
\hline
\end{tabular}

Note. $n=632$. Because participants did not provide usable responses to some questions $n$ for individual items range from 618 to 630 . Responses were made on a scale ranging from 1 (of least importance) to 10 (of greatest importance). HMO, Health Maintenance Organization. 
fined as responding to fewer than half of the items), leaving 632 participants for analysis. A small number of responses was recoded for purposes of analysis; for example, three ratings of 0 were changed to 1 (the instructions specified a $1-10$ scale), and a response of "10-15 years" was coded as 12.5 .

\section{Sample characteristics}

Table 2 shows a breakdown of the sample characteristics. As the table indicates, the sample was quite heterogeneous; participants came from a variety of racial, religious, and educational backgrounds. The frequency with which participants visited their PCD was moderately high. Nearly three-quarters of participants $(70.2 \%)$ had made one to five visits in the past year; the remainder was roughly equally split between those who had visited their PCD six or more times and those who had not been to their PCD at all.

Forty-nine percent of participants reported that they chose an insurance company that would allow them to use a particular PCD, while 51\% reported choosing an insurance company before selecting a PCD from the company's list (cf. Gibbs et al. 1996). Participants felt that they had much, but not all, of the information that was relevant to their PCD selection. In response to the question, "On a scale of 1-10, how much of the information that you would like to have, ideally, did you actually have when you chose your current physician?" the mean rating was $6.30(S D=2.70)$.

\section{Importance of factors in PCD choice}

Table 1 shows mean ratings for the 23 items. The variable that participants deemed most important to their choice of a PCD was whether or not the doctor was board certified. In general, variables relating to the doctor's professional expertise (e.g. board certification, specialization) were rated highly, while factors relating to the doctor's individual characteristics (e.g. gender, religion, marital status) were considered relatively unimportant.

An exploratory factor analysis with Varimax rotation was performed to identify possible underlying factors. The best model, which explained 33\% of the variance, contained three factors with eigen-
Table 2 Sample characteristics

\begin{tabular}{lr}
\hline Characteristic & Per cent \\
\hline Gender & \\
Female & 81.6 \\
Male & 18.4 \\
Race & \\
White & 83.6 \\
Black & 15.3 \\
Other & 1.2 \\
Marital status & \\
Never married & 24.5 \\
Married & 67.2 \\
Separated/divorced & 8.3 \\
Education & \\
High school & 14.6 \\
Some college & 31.6 \\
Bachelor's degree & 38.7 \\
Post-graduate degree & 15.1 \\
Religion & \\
Catholic & 42.4 \\
Protestant & 54.4 \\
Other* \\
Visits to PCD in past year & 3.2 \\
None & \\
1-5 & 14.4 \\
6-10 & 70.2 \\
$>10$ & 8.1 \\
\hline
\end{tabular}

*For race, the 'Other' category includes Hispanics and AsianAmericans; for religion, 'Other' includes Jews, Muslims, Buddhists, atheists and agnostics.

values greater than 1.0 (Table 3). Four items (how long the doctor had been practicing, which Health Maintenance Organization the doctor was in, where the doctor attended medical school, and specialization) did not load strongly on any of the three factors (factor loadings $<0.3$ ). The remaining 19 items were divided roughly equally among factors representing professional skill (e.g. neatness of the doctor and the doctor's office, board certification), explaining $11.5 \%$ of the variance; office management (e.g. availability of evening and weekend office hours), explaining $11.0 \%$ of the variance; and personal characteristics (e.g. race, religion), explaining $10.5 \%$ of the variance. Two items (waiting time for an appointment and at an office visit) loaded onto more than one factor (Table 3).

Overall, the results of the factor analysis suggest that the majority of items did tap into underlying variables reflective of three different aspects 
Table 3 Factor analysis

\begin{tabular}{|c|c|c|c|}
\hline Item & Professional skill & $\begin{array}{c}\text { Factor loadings } \\
\text { Office management }\end{array}$ & Personal characteristics \\
\hline Appearance of office & 0.745 & & \\
\hline Appearance of doctor & 0.697 & & \\
\hline Board certified & 0.544 & & \\
\hline Waiting at office & 0.489 & 0.354 & \\
\hline Hospital(s) & 0.477 & & \\
\hline Waiting for appointment & 0.458 & 0.523 & \\
\hline Recommendations & 0.333 & & \\
\hline Malpractice cases & 0.303 & & \\
\hline Evening office hours & & 0.806 & \\
\hline Weekend office hours & & 0.759 & \\
\hline Cost of the care & & 0.445 & \\
\hline Proximity of office & & 0.418 & \\
\hline Number of doctors in office & & 0.348 & \\
\hline Doctor's native country & & & 0.749 \\
\hline Doctor's ethnicity or race & & & 0.739 \\
\hline Doctor's marital status & & & 0.565 \\
\hline Doctor's age & & & 0.515 \\
\hline Doctor's religion & & & 0.524 \\
\hline Doctor's gender & & & 0.387 \\
\hline
\end{tabular}

relevant to the choice of a PCD: professional skill, office management, and personal characteristics. A comparison of Tables 2 and 3 indicates that items comprising the professional skill factor tended to be rated highest (it contained the four highest-rated individual items), followed by those items making up the office management factor. Items comprising the personal characteristics factor tended to receive the lowest ratings of importance; the six lowest-rated items constituted this factor.

\section{The relationship between doctor and patient characteristics}

A number of planned comparisons were run to test the hypothesis that patients' own characteristics would influence the weight given to characteristics possessed by their PCD. There was little support for this hypothesis. Specifically, men and women did not differ in the importance given to their PCD's gender, $t(602)=0.21$; whites and minorities did not differ in the importance given to race, $t(589)$ $=0.51$; and differences in participants' marital status did not predict ratings of the importance of the PCD's marital status, $F(2,594)=1.36$ (all $P>0.2$ ).
The only demographic variable to affect participants' ratings was religion: Protestants rated their PCD's religion as more important $(M=2.42, S D=$ 2.59) than Catholics $(M=1.72, S D=1.83), t(569)=$ $3.59, P<0.001$ (19 participants reporting "Other" religions were dropped for this analysis), although religion was rated as relatively unimportant by all participants.

\section{Discussion}

The results of the present study indicate that consumers are quite rational in the variables they deem important to their choice of a PCD. Factor analysis indicated that various features of the decision reduce to three principal factors: professional skill, office management, and personal characteristics. Participants were most concerned about variables relating to doctors' professional competence, followed by pragmatic variables relating to office management; doctors' personal characteristics were viewed as relatively unimportant.

These findings partially support previous research that has found patients to view pragmatic concerns, such as convenience, as important, while also illus- 
trating the negligible role of doctors' personal characteristics (Billinghurst \& Whitfield 1993; Salisbury 1989). The importance attached to recommendations (the fourth highest-rated variable) is also consistent with previous findings (e.g. Hoerger \& Howard 1995; Lupton et al. 1991; Salisbury 1989). However, the present study found variables related to doctors' professional expertise to be of greatest perceived importance, which previous studies have largely ignored (but see Hoerger \& Howard 1995). Thus, patients want to have information that is relevant both to the quality of healthcare they will receive and to the ease with which they can obtain it.

More problematic is the fact that patients have little access to this desired information. Salisbury (1989) found that although $74 \%$ of patients thought that it was easy or fairly easy to find out about doctors' practices before they registered, $40 \%$ of them had not spoken to anyone before choosing a practice. Only $11 \%$ actually contacted the practice to ask questions, with another $2 \%$ asking questions of their previous doctor. Most of the remainder obtained information about the practice they chose from friends or family. This lack of information search is true for patients choosing a specialist as well (Hoerger \& Howard 1995). These figures are perplexing as they indicate that patients take little responsibility for being well-informed about their healthcare decisions, despite their belief that such information is not hard to come by (Gibbs et al. 1996; Lubalin \& Harris-Kojetin 1999). Salisbury concludes that most patients may avoid gathering the necessary information until they have to (i.e. when they become sick), at which point they no longer have the time to do so. In other words, "choosing a doctor may be less analogous to the consumer's choice of a new car but more like finding a local garage quickly when the car breaks down" (Salisbury 1989; p. 610).

Thus, patients are unlikely to know, or be able to learn without some effort, certain facts, such as whether the doctor is board certified or has been the target of malpractice claims. They will typically not learn other facts, such as waiting times or the neatness of the doctor and office, until they have already committed to using a particular doctor. Participants appeared to be aware of this problem; by their own admission, they did not have all of the information that they would like to have had in choosing a PCD (mean of 6.30, with 10 representing the ideal amount of information). They might not be the most savvy consumers (Lupton et al. 1991; Salisbury 1989), and they know it. Although the information they would like to have is very sensible and helpful, the information that they actually do use in making their choice is less than optimal (Lubalin \& Harris-Kojetin 1999).

Of course, people do not have perfect access to the reasons underlying their behavior (Fischhoff, Slovic, \& Lichtenstein 1988; Nisbett \& Wilson 1977). Because hypothetical judgment and actual choice are not synonymous (Einhorn \& Hogarth 1981), it is possible that the factors participants retrospectively judged to be important in their choice of a PCD were different from those that actually were. Although it is difficult to study actual decision processes "online" (Ebbesen \& Konecni 1980) - especially for decisions that may not occur at a discrete point in time, as in choosing a PCD - the present findings could be corroborated by two means. First, further simulation research needs to manipulate variables relevant to PCD choice in a hypothetical decision task, in order to determine the correspondence between the factors that influence participants' simulated judgments and the factors they retrospectively report as being important to those decisions. Second, external validity would be heightened by studying individuals who are in the actual process of choosing a PCD (e.g. new employees).

Choosing a PCD is but the first - though arguably the most important - decision facing patients in their consumption of healthcare services (Hibbard et al. 1997). Attention should be paid as well to patients' selection of a specialist, which may be influenced by other factors (cf. Hoerger \& Howard 1995). For example, patients may weigh doctors' gender more heavily when choosing an obstetrician or urologist than when choosing a PCD. However, with the increasing extent to which PCDs play a "gatekeeper" role in a managed care environment, patients are likely to be less active choosers in this situation; and of course, only a subset of patients using a PCD require a specialist. 
It is also worth examining the correspondence between the factors patients consider in choosing a doctor and the factors that lead them to change doctors. Although patients rarely change healthcare providers (Billinghurst \& Whitfield 1993), variables that patients perceive as important in the initial selection - such as professional skill — should logically be the same as those that influence changing (e.g. a perceived lack of skill). Billinghurst \& Whitfield's (1993) results suggest, however, that the importance of doctors' competence may be outweighed by matters of convenience when making such a change.

In conclusion, the results of the present study suggest that the factors patients perceive as most important to their choice of a doctor - the doctor's professional skill and office management practices - are also those that have the greatest effect on the quality of healthcare the patients will receive. Once people are aware of what information and goals are important to them, they are then able to make effective decisions and competently manage their affairs (Fischhoff \& Downs 1997). The present findings add to the literature on how patients make specific healthcare decisions, such as whether to vaccinate (Asch et al. 1994) or which treatment option to choose (Mazur \& Hickam 1990). A better understanding of the factors that influence people's initial choice of healthcare providers can provide them with the resources to make better choices in this arena (Hibbard et al. 1997; Lubalin \& HarrisKojetin 1999). It now remains to find an efficient way to provide them with the relevant information they desire.

\section{Acknowledgements}

We are grateful to the East Baton Rouge Parish Medical Society which provided seed money for this research. We gratefully acknowledge the assistance of Dr Alan Joseph of Neurological Associates, the Perkins Road Wal-Mart in Baton Rouge, and the Junior League of Baton Rouge in procuring participants. We thank Bryan Ballard for his assistance in collecting and entering data, and Charles Grenier for his collaboration in designing the questionnaire.

\section{References}

Arkes H.R., Wortmann R.L., Saville P.D. \& Harkness A.R. (1981) Hindsight bias among physicians weighing the likelihood of diagnoses. Journal of Applied Psychology 66, 252-254.

Asch D.A., Baron J., Hershey J.C., Kunreuther H., Meszaros J., Ritov I. \& Spranca M. (1994) Omission bias and pertussis vaccination. Medical Decision Making 14, 118-123.

Billinghurst B. \& Whitfield M. (1993) Why do patients change their general practitioner? A postal questionnaire study of patients in Avon. British Journal of General Practice 43, 336-338.

Christensen C., Heckerling P., Mackesy-Amiti M.E., Bernstein L.M. \& Elstein A.S. (1995) Pervasiveness of framing effects among physicians and medical students. Journal of Behavioral Decision Making 8, 169-180.

Dawson N.V. \& Arkes H.R. (1987) Systematic errors in medical decision making: judgment limitations. Journal of General Internal Medicine 2, 183-187.

Dawson N.V., Arkes H.R., Siciliano C., Blinkhorn R., Lakshmanan M. \& Petrelli M. (1988) Hindsight bias: an impediment to accurate probability estimation in clinicopathologic conferences. Medical Decision Making 8, 259-264.

Detmer D.E., Fryback D.G. \& Gassner K. (1978) Heuristics and biases in medical decision-making. Journal of Medical Education 53, 682-683.

Ebbesen E.B. \& Konecni V.J. (1980) On the external validity of decision-making research. What do we know about decisions in the real world? In: Wallsten T.S., ed. Cognitive Processes in Choice and Decision Behavior, pp. 21-45. Erlbaum, Hillsdale, NJ.

Einhorn H.J. \& Hogarth R.M. (1981) Behavioral decision theory: processes of judgment and choice. Annual Review of Psychology 32, 53-88.

Elstein A.S., Shulman L.S. \& Sprafka S.A. (1978) Medical Problem Solving. An Analysis of Clinical Reasoning. Harvard University Press, Cambridge, MA.

Fischhoff B. \& Downs J. (1997) Accentuate the relevant. Psychological Science 8, 154-158.

Fischhoff B., Slovic P. \& Lichtenstein S. (1988) Knowing what you want. Measuring labile values. In: Bell D.E., Raiffa H. \& Tversky A,, eds. Decision Making: Descriptive, Normative, and Prescriptive Interactions, pp. 398-421. Cambridge University Press, Cambridge. 
Fitten L.J., Lusky R. \& Hamann C. (1990) Assessing treatment decision-making capacity in elderly nursing home residents. Journal of the American Geriatrics Society 38, 1097-1104.

Gibbs D., Sangl J. \& Burrus B. (1996) Consumer perspectives on information needs for health plan choice. Health Care Financing Review 18, 55-73.

Hibbard J., Slovic P. \& Jewett J. (1997) Informing consumer decisions in health care: implications from decision-making research. Milbank Quarterly 75, 395413.

Hoerger T.J. \& Howard L.Z. (1995) Search behavior and choice of physician in the market for prenatal care. Medical Care 33, 332-349.

Hofmann J.C., Wenger N.S., Davis R.B., Teno J., Connors A.F., Desbiens N., Lynn J. \& Phillips R.S. (1997) Patient preferences for communication with physicians about end-of-life decisions. Annals of Internal Medicine 127, 1-12.

Lubalin J.S. \& Harris-Kojetin L.D. (1999) What do consumers want and need to know in making health care choices? Medical Care Research and Review 56 (Suppl. I), 67-102.

Lupton D., Donaldson C. \& Lloyd P. (1991) Caveat emptor or blissful ignorance? Patients and the consumerist ethos. Social Science \& Medicine 33, 559568.
Mazur D.J. \& Hickam D.H. (1990) Treatment preferences of patients and physicians: influences of summary data when framing effects are controlled. Medical Decision Making 10, 2-5.

McNeil B.J., Pauker S.G. \& Tversky A. (1984) On the framing of medical decisions. In: Bell D.E., Raiffa H. \& Tversky A., eds. Decision Making. pp. 562568. Cambridge University Press, Cambridge.

New evidence that managed care is to blame? (1997) May 12. Medical Economics 74, 45.

Nisbett R.E. \&Wilson T.D. (1977) Telling more than we can know: verbal reports on mental processes. Psychological Review 84, 231-259.

Pauker S.G. \& McNeil B.J. (1981) Impact of patient preferences on the selection of therapy. Journal of Chronic Diseases 34, 77-86.

Salisbury C.J. (1989) How do people choose their doctor? British Medical Journal 299, 608-610.

Ubel P.A. \& Loewenstein G. (1997) The role of decision analysis in informed consent: choosing between intuition and systematicity. Social Science \& Medicine 44, 647-656.

Wolinsky F. D. \& Steiber S.R. (1982) Salient issues in choosing a new doctor. Social Science \& Medicine $16,759-767$. 